\title{
RESULTS OF USE OF METHODS TO INCREASE THE WELLS PRODUCTIVITY Bissembayeva K.T. ${ }^{1}$, Aisayeva T.S. ${ }^{2}$, Nur N. ${ }^{3}$ (Republic of Kazakhstan) Email: Bissembayeva340@scientifictext.ru
}

\author{
${ }^{1}$ Bissembayeva Karlygash Tanbayevna - PhD in technical science, Associate Professor; \\ ${ }^{2}$ Aisayeva Tolkyn Satzhanovna - Doctoral Student; \\ ${ }^{3}$ Nur Nauryzbai - Undergraduate, \\ OIL AND GAS BUSINESS AND GEOLOGY DEPARTMENT, \\ CASPIAN STATE UNIVERSITY OF TECHNOLOGY AND ENGINEERING NAMED AFTER SH. YESSENOV, \\ AKTAU, REPUBLIC OF KAZAKHSTAN
}

\begin{abstract}
: at present, fields with complex geological and physical conditions, as well as high-viscosity oil, are under development. In this regard, the most important problem of increasing the completeness of extracting oil from the bowels is being solved. In this paper, the issue of reason of reducing formation permeability and well productivity is considered. The authors analyze the efficiency of the application of technologies for the restoration of well productivity at Asar deposit (Kazakhstan), such as hot water treatment with the addition of surfactant "Rauan-100" and well treatment with chemical compositions - emulsion of complex influence.

Keywords: reservoir, permeability, productivity, bottomhole well zone, thermal impact, treatment, hot water, injection well, emulsion, production wells.

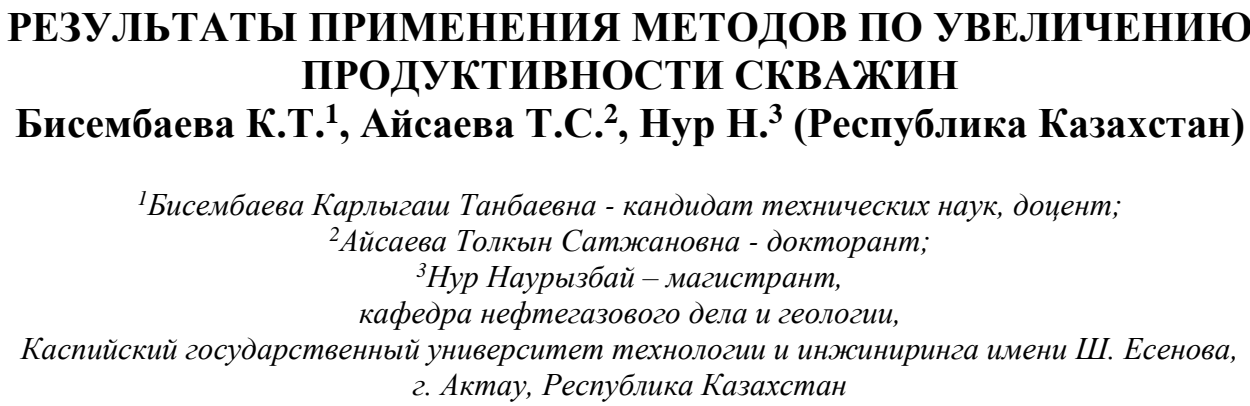

Аннотация: в настоящее время в разработке находятся месторождения со сложными геологофизическими условиями, а также содержащие высоковязкие парафинистые нефти. В связи с этим решается важнейшая проблема увеличения полноты извлечения нефти из недр. В данной работе рассматривается вопрос причины снижения проницаемости пластов и продуктивности скважин. Приводится анализ эффективности применения технологий для восстановления продуктивности скважин на месторождении Асар (Казахстан), таких как обработка горячей водой с добавлением поверхностно-активного вещества (ПАВ) «Рауан -100» и обработка скважин химическими композициями - эмульсией комплексного воздействия.

Ключевые слова: пласт, проницаемость, продуктивность, призабойная зона скважинь, тепловое воздействие, обработка, горячая вода, эмульсия, нагнетательные скважины, добывающие скважинь.

УДК 622. 276.4

Большинство нефтяных месторождений Казахстана, находящихся в разработке, содержат высоковязкие парафинистые нефти. Процесс извлечения таких углеводородов сопровождается факторами, которые осложняют разработку месторождений в целом и влияют на ее эффективность.

Значительная доля осложнений при эксплуатации месторождений происходит из-за парафиновых отложений в призабойной зоне скважин. Это, конечно же, влияет на фильтрационные свойства пластов.

Многочисленными исследованиями, проведенными на нефтяных месторождениях, доказано существенное влияние гидропроводности и проницаемости призабойной зоны пласта (ПЗП) на продуктивность скважин $[1,2]$. С учетом многообразия геолого-физических и технологических условий разработки месторождений призабойная зона пласта в течение всего периода работы скважины подвергается различным физико-химическим, биологическим и другим изменениям, влияющим на гидропроводность ПЗП. В этой связи проницаемость призабойной зоны пласта практически никогда не является постоянной, а изменение ее во времени идет, как правило, в сторону снижения [3].

На месторождении Асар с целью удаления отложений в призабойной зоне пласта и подземном оборудовании, а также восстановления продуктивности скважин проводятся профилактические обработки горячей водой (ОГВ) с добавлением поверхностно-активного вещества (ПАВ) «Рауан -100» и обработки скважин химическими композициями - эмульсией комплексного воздействия (ЭКВ) [4]. 
Как следует из промысловых данных, объем проводимых мероприятий составил в целом 2645 скважино-операций, в том числе: ЭКВ - 9 скважино-операций, ОГВ - 2636 [4]. Фонд скважин, осложненных асфальтено-смолопарафиновыми отложениями (АСПО) на протяжении анализируемого периода увеличивается, т.е. проблема парафинизации на месторождении остается актуальной.

Проведен анализ изменения коэффициента продуктивности по скважинам до и после проведения закачки ЭКВ. Результаты анализа представлены в таблице 1 [4].

Таблица 1. Изменение коэффициента продуктивности до и после закачки ЭКВ

\begin{tabular}{|c|c|c|c|c|c|c|}
\hline \multirow{2}{*}{$\begin{array}{l}\text { № } \\
\text { ПI/I }\end{array}$} & \multirow{2}{*}{$\begin{array}{c}\text { № } \\
\text { скв }\end{array}$} & \multirow{2}{*}{ Гор } & \multirow{2}{*}{$\begin{array}{c}\text { Интервал } \\
\text { перфорации, м }\end{array}$} & \multirow{2}{*}{$\begin{array}{c}\text { Дата } \\
\text { проведения }\end{array}$} & \multicolumn{2}{|c|}{ К прод., м³/сут. *МПа } \\
\hline & & & & & до обработки & после обработки \\
\hline 1 & 208 & 96 & $2000-2033$ & 31.07 .10 & 3,2 & 6,8 \\
\hline 2 & 139 & $4 \mathrm{a}$ & $1786-1803$ & 17.12 .10 & 1,02 & 1,6 \\
\hline 3 & 117 & $2 \mathrm{a}$ & $1574-1588$ & 17.07.10 & 1,6 & 1,0 \\
\hline 4 & 75 & $10 \mathrm{a} 6$ & $2070-2082$ & 31.03 .10 & 4,0 & 3,9 \\
\hline 5 & 56 & $2+3$ & $1655-1693$ & 26.10 .10 & 8,5 & 6,9 \\
\hline 6 & 434 & 106 & $2143-2150$ & 04.01 .13 & 3,2 & 5,9 \\
\hline 7 & 117 & $2 \mathrm{a}$ & $1577-1585$ & 02.09 .13 & 2,2 & 0,6 \\
\hline 8 & 172 & 11 & $2190-2195$ & 16.09 .14 & 3,6 & 1,3 \\
\hline
\end{tabular}

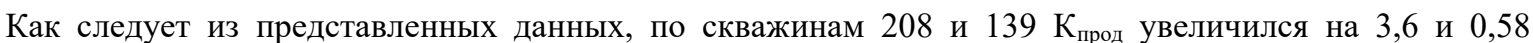
$\mathrm{M}^{3} /$ сут $*$ МПа.

Самым распространенным методом на месторождениях является тепловой метод депарафинизации скважин с использованием горячей воды (ОГВ). Процесс расплавления, растворения и удаления АСПО потоком движущейся горячей жидкости с внутренней поверхности НКТ осуществляется циркуляцией теплоносителя по каналам ствола скважины при непосредственной ее закачке в НКТ или через затрубное пространство.

Следует сказать, что эффективная эксплуатация нефтепромыслового оборудования характеризуется величиной межочистного периода работы скважин (МОП), т.е. отрезком времени между очистками. Для определения эффективности проводимых профилактических мероприятий проанализированы данные по количеству обработок на скважинах и на основании анализа проведен расчет межочистных периодов по скважинам, обработанных ОГВ.

Для определения эффективности проведенных ОГВ рассчитан межочистной период работы скважин (МОП). МОП определялся по количеству дней безаварийной работы скважин и рассчитывался по формуле:

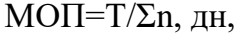

где Т- отработанное время, дни; n-количество обработок.

Результаты расчета межочистных периодов работы скважин, обработанных ОГВ за один год, представлены в таблице 2 [4].

Таблица 2. Результаты применения ОГВ

\begin{tabular}{|c|c|c|c|c|c|c|}
\hline \multirow{2}{*}{$\begin{array}{c}\text { Количество } \\
\text { анализируемых } \\
\text { скважин }\end{array}$} & \multirow{2}{*}{$\mathbf{Q}_{ж,} \mathbf{T} / \mathbf{c y T}$} & \multirow{2}{*}{ Показатели } & \multicolumn{4}{|c|}{ Интервалы обводненности, \% } \\
\hline & & & $0-30$ & $31-60$ & 61-90 & более 90 \\
\hline \multirow{2}{*}{33} & \multirow{2}{*}{$\mathbf{0 - 3 0}$} & Кол-во скв & 13 & 9 & 8 & 3 \\
\hline & & МОП & 102 & 71 & 118 & 155 \\
\hline \multirow{2}{*}{12} & \multirow{2}{*}{$31-60$} & Кол-во скв & 3 & 3 & 6 & - \\
\hline & & МОП & 93 & 132 & 301 & - \\
\hline \multirow{2}{*}{2} & \multirow{2}{*}{$61-90$} & $\begin{array}{c}\text { Кол-во скв } \\
\text { МОП } \\
\end{array}$ & 1 & 1 & - & - \\
\hline & & МОП & 181 & 163 & - & - \\
\hline Итого: 47 & & Cp. & 125 & 122 & 209 & 155 \\
\hline
\end{tabular}


Как показал проведенный анализ за анализируемый период, интенсивной парафинизации подвержены группы скважин (Qж - от 0 до 30 т/сут и от 30 до 60 т/сут) и обводненностью от 0 до $60 \%$. МОП по этой группе скважин изменяется в пределах от 12 до 128 суток. С увеличением обводненности интенсивность парафинизации снижается и средний МОП по этой группе скважин составляет от 22 суток до 253 суток.

В целом, проводимые тепловые промывки позволяют стабилизировать дебит и восстановить продуктивность скважины на определенный период.

\section{Сиисок литературы / References}

1. Михайлов Н.Н. Основы комплексного изучения околоскважинных зон для повышения эффективности процессов нефтеизвлечения: Диссертация д-ра техн. наук. М., 1994. 370 с.

2. Подгорнов B.M. Формирование призабойной зоны с целью повышения продуктивности нефтегазодобывающих скважин: Диссертация д-ра техн. наук. М.-, 1992. 192 с.

3. Ибрагимов Л.Х., Мищенко И.Т., Челоянц Д.К. Интенсификация добычи нефти. Москва «Наука», 2000. $414 \mathrm{c}$.

4. Промысловые данные по месторождению Асар, 2014. 